\title{
Laparoscopic resection for Meckel's diverticulum causing intestinal obstruction
}

Türker Karabuğa' ${ }^{1}$ İsmail Özsan¹, Ömer Yoldaș', Erkan Șahin², Önder Limon³ , Ünal Aydın

\begin{tabular}{|c|c|}
\hline ABSTRACT & $\begin{array}{l}\text { Meckel's diverticulum (MD) is the most common congenital anomaly of the gastrointestinal system with an estimated inci- } \\
\text { dence of approximately } 2 \% \text { of the population. Although most cases are asymptomatic, it has the potential to create complica- } \\
\text { tions, such as hemorrhage, inflammation, intestinal obstruction, perforation, and intussusception. Meckel's diverticulum is } \\
\text { generally diagnosed incidentally or upon investigation of unexplained gastrointestinal bleeding, perforation, inflammation, } \\
\text { or obstruction for both pediatric and adult patients. Complications are often present as surgical emergencies and require re- } \\
\text { section of the diseased intestinal segment. In doubtful cases, laparoscopy should be the surgical method for both diagnosing } \\
\text { and treating MD. Here we present a case of MD causing intestinal obstruction and that was treated by laparoscopic resection. } \\
\text { Keywords: Meckel's diverticulum, laparoscopy, intestinal obstruction }\end{array}$ \\
\hline
\end{tabular}

Cite this paper as:

Karabuğa I, Özsan I, Yoldaş

0̈, Şahin E, Limon Ö, Aydın

Ü. Laparoscopic resection for

Meckel's diverticulum causing

intestinal obstruction. Turk J

Surg 2017; 33: 224-226.

'Department of General Surgery, İzmir University School of Medicine, Medicalpark Hospital, İzmir, Turkey

${ }^{2}$ Department of Radiology, Izmir University School of Medicine, Medicalpark Hospital, İzmir, Turkey

${ }^{3}$ Department of Emergency Medicine, İzmir University School of Medicine, Medicalpark Hospital, İzmir, Turkey

\section{Address for Correspondence} Ünal Aydın

e-mail: unalaydinmd@gmail.com

Received: 08.09.2014

Accepted: 26.12 .2014

Available Online Date: 06.07.2015

@C Copyright 2017

by Turkish Surgical Association

\section{INTRODUCTION}

Meckel's diverticulum (MD) is a true diverticulum derived from a persistent vitellointestinal duct and was first described by Johann Meckel in $1812(1,2)$. Meckel's diverticulum occurs on the antimesenteric border of the ileum and in the majority of cases, within $90 \mathrm{~cm}$ from the ileoceacal valve. Most cases are asymptomatic with an overall lifetime risk of complications reported at approximately $6.4 \%$ (3). Bleeding is the most common presentation in children, representing $50 \%$ of MD-related complications among patients younger than 18 years. Intestinal obstruction is the most common presentation in adults with Meckel's diverticula. Diverticulitis, present in $20 \%$ of patients with symptomatic Meckel's diverticula, is associated with a clinical syndrome that is indistinguishable from acute appendicitis (4). Although complications due to MD are rare, they often present as surgical emergencies (5). These complications often warrant surgical resection of the diseased segment. Meckel's diverticulum is generally diagnosed incidentally or upon investigation of unexplained gastrointestinal bleeding, perforation, inflammation, or obstruction for both pediatric and adult patients. Here we present a case of MD causing intestinal obstruction and that was treated by laparoscopic resection.

\section{CASE PRESENTATION}

A 24-year old man with no significant medical history and no prior surgical history presented with complaints of abdominal pain, nausea, and vomiting to our emergency unit. The laboratory examination revealed mild leukocytosis (white blood cell count, 13.700). The plain abdominal radiograph revealed dilated small bowel loops with multiple air-fluid levels showing an intestinal obstruction. On physical examination, there was a mild abdominal distention particularly in the upper quadrants of the abdomen with no signs of abdominal rebound tenderness. Abdominal contrast enhanced computed tomography revealed diffuse wall thickness of distal intestinal segments and proximally dilated intestinal segments (Figure 1). Because of the patient's age and clinical history of having no previous surgical history, the preoperative diagnosis was Crohn's intestinal involvement or gastrointestinal lymphoma. Instead of an open surgical procedure, we decided to perform a diagnostic laparoscopy, and an informed written consent was obtained from the patient.

Laparoscopic exploration was performed through a three-trocar operative technique (using a 10-mm optical trocar at the infra-umbilical region; a 5-mm operating trocar at the supra-pubic region, which was changed to a 12-mm trocar during stapling; and a 5- $\mathrm{mm}$ operative trocar at the right lower quadrant on McBurney's point) with an angled $\left(30^{\circ}\right)$ laparoscope. Entrance to the abdomen was achieved by an open technique. First, the ileocecal valve was found, and an exploration was conducted through the proximal intestinal segments. At the exploration, a w-shaped intestinal obstruction was observed approximately $100 \mathrm{~cm}$ proximal to the ileocecal valve. After blunt dissection of the intestine, an inflamed MD was found to be the reason of the intestinal obstruction (Figure 2). The vascular pedicle of the resected intestinal segment was ligated using Ligasure ${ }^{T M}$ (Covidien, Colorado, USA). The resection of MD was performed using $60 \mathrm{~mm}$ Endo GIA ${ }^{\mathrm{TM}}$ (Blue, $3.5 \mathrm{~mm}$, Covidien, Colorado, USA) with additional reinforcement (Figure 3). The pathological specimen was extracted from the suprapubic port incision in an endoscopic bag. A drain was placed at the rectovesical fossa, and the operation was terminated. There was no more 


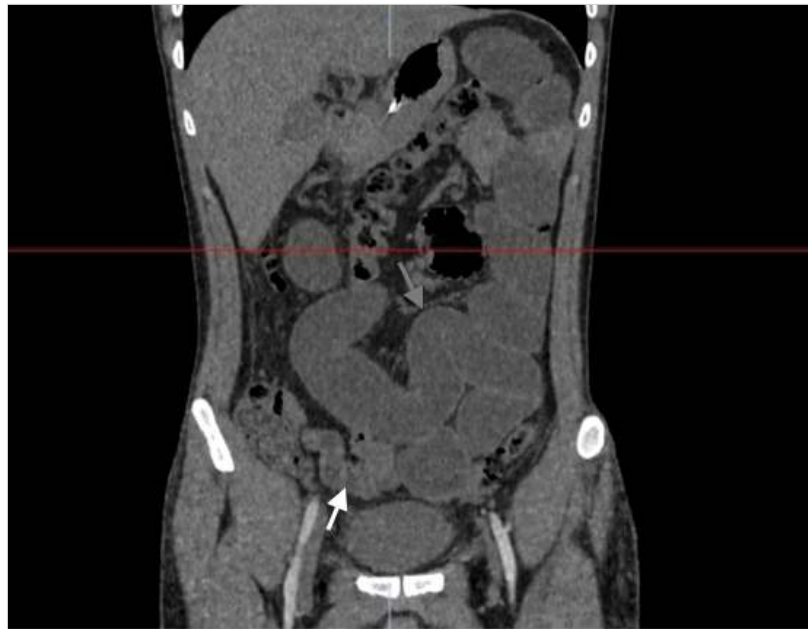

Figure 1. Axial contrast-enhanced arterial images of the abdominal computed tomography scan; diffuse wall thickness of distal intestinal segments (white arrow) and dilatation of the proximal intestinal segments (gray arrow)

than $100 \mathrm{~mL}$ bleeding during the operation. The operation duration was 78 min overall. Finding the obstructive intestinal segment in a distended abdomen was the hard part of the operation. The operation was performed in the Trendelenburg position to achieve an easier exploration and resection. The postoperative course was uneventful, and the patient was discharged on the third postoperative day.

\section{DISCUSSION}

Meckel's diverticulum is a congenital, intestinal blind pouch that results from an incomplete obliteration of the vitelline duct during the fifth week of gestation. It is a true diverticulum that usually arises from the antimesenteric border of the distal part of the ileum and contains all layers of the normal intestinal wall. Although it generally remains silent, life-threatening complications may arise, making it important to have a detailed knowledge of its anatomical and pathophysiological structure and properties to deal with such complications (6). Meckel's diverticulum is extremely difficult to diagnose both clinically and radiologically as the symptoms and imaging features are nonspecific. Hemorrhage is the most frequent complication of the condition in the pediatric population and arises secondary to ulcerations caused by acid secretion from the ectopic mucosa. Obstruction because of intussusception or adhesions, ulceration, and inflammation (diverticulitis) occur more frequently among adults (7). Complications appear more frequently among males, with a reported 3-4 times greater incidence in males.

Cullen et al. (3) studied the outcomes of surgical management of MD-related complications and determined that the operative mortality and morbidity rates were $2 \%$ and $12 \%$, respectively, and that the cumulative risk of long-term postoperative complications was 7\%; in contrast, the analysis of patients receiving incidental diverticulectomy showed that the operative mortality, morbidity, and risk of long-term postoperative complications were lower $(1 \%, 2 \%$, and $2 \%$, respectively). It is generally recommended that MD discovered incidentally during operation should be removed, regardless of the patient's age.

Sasikumar et al. (8) reported a case of small bowel obstruction due to the torsion of gangrenous MD, and they performed

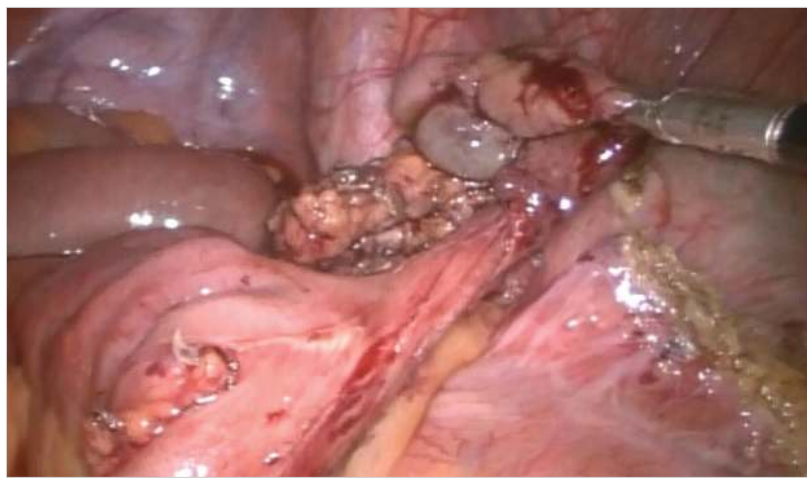

Figure 2. Intraoperative image of the inflamed Meckel's diverticulum

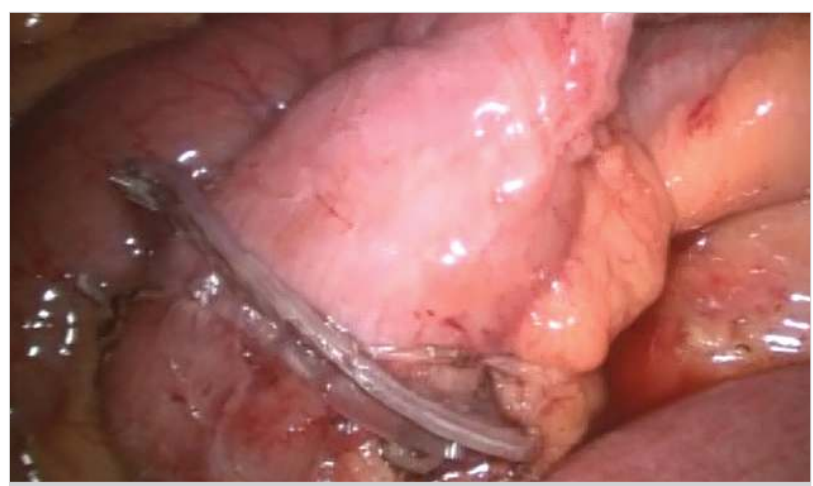

Figure 3. Image of the intestine after the laparoscopic resection of Meckel's diverticulum

resection and anastomosis by an open approach. Ding et al. (9) reported the role of laparoscopy on the surgical treatment of perforated MD, and they found it to be safe and effective for diagnosis and the therapeutic role. Alemayehu et al. (10) reported a retrospective analysis of laparoscopically treated complicated MD in patients. Eight of these patients had intestinal obstruction and were laparoscopically treated without complication.

The preoperative diagnosis of MD is usually difficult because of its various clinical presentations. Most of the cases are misdiagnosed as acute appendicitis. Incidentally diagnosed MD and complicated MD require a surgical intervention. Usually, McBurney's point or an inferior umbilical median incision is used for laparotomy, and an open approach is used in the treatment of MD.

\section{CONCLUSION}

In patients with doubtful diagnosis, as in our case, laparoscopy is a feasible, safe, and effective surgical method for diagnosing $M D$, and it also helps treat the condition.

Informed Consent: Written informed consent was obtained from patient who participated in this case.

Peer-review: Externally peer-reviewed.

Author Contributions: Concept - T.K., I.Ö.; Data Collection and/or Processing - I.Ö., Ö.L.; Analysis and/or Interpretation - Ö.Y.; Literature Review - E.Ş., Ö.Y.; Writer - Ö.Y.; Critical Review - Ü.A.

Conflict of Interest: No conflict of interest was declared by the authors. 
Karabuğa et al.

Laparoscopy for Meckel's diverticulum

Financial Disclosure: The authors declared that this study has received no financial support.

\section{REFERENCES}

1. Limas C, Seretis K, Soultanidis C, Anagnostoulis S. Axial torsion and gangrene of a giant Meckel's diverticulum. J Gastrointestin Liver Dis 2006; 15: 67-68.

2. Cullen JJ, Kelly KA. Current management of Meckel's diverticulum. Adv Surg 1996; 29: 207-214.

3. Cullen JJ, Kelly KA, Moir CR, Hodge DO, Zinsmeister AR, Melton $\mathrm{LJ} 3^{\text {rd }}$. Surgical management of Meckel's diverticulum. An epidemiologic, population-based study. Ann Surg 1994; 220: 564-569. [CrossRef]

4. Whang EE. Small İntestine. In Schwartz's Principal of Surgery. 9th edition. Edited by Charles Brunicardi F, Andrsen D, Billiar T, Dunn D, Hunter J, Matthews J, Pollock RE. New York: McGraw Hill Publishing 2010: 1937-1940.
5. Dumper J, Mackenzie S, Mitchell P, Sutherland F, Quan ML, Mew D. Complications of Meckel's diverticula in adults. Can J Surg 2006; 49 : 353-357.

6. Sharma RK, Jain VK. Emergency surgery for Meckel's diverticulum. World J Emerg Surg 2008; 13: 27. [CrossRef]

7. Sagar J, Kumar V. Meckel's diverticulum: a systematic review. J R Soc Med 2006; 99: 501-505. [CrossRef]

8. Sasikumar K, Noonavath RN, Sreenath GS, Maroju NK. Axial torsion of gangrenous Meckel's diverticulum causing small bowel obstruction. J Surg Tech Case Rep 2013; 5: 103-105. [CrossRef]

9. Ding Y, Zhou Y, Ji Z, Zhang J, Wang Q. Laparoscopic management of perforated Meckel's diverticulum in adults. Int J Med Sci 2012; 9: 243-247. [CrossRef]

10. Alemayehu H, Stringel G, Lo IJ, Golden J, Pandya S, McBridge W, et al. Laparoscopy and complicated meckel diverticulum in children. JSLS 2014; 18: pii: e2014.00015. 